\title{
Website Pengolahan Nilai Siswa menggunakan Konsep Model - View - Controller pada LIA Pamulang
}

\author{
Nana Sutrisna Hadinata ${ }^{1)}$, Fitriyani ${ }^{2)}$ \\ ${ }^{1), 2)}$ Sistem Informasi, Universitas BSI \\ jalan sekolah internasional 1-2 antapani, kec. Kiara condong, kel. Cicaheum 40282 \\ Email : nanasutrisnahadinata@gmail.com ${ }^{1)}$,fitriyani.fitriyani@hotmail.co.id ${ }^{2}$
}

\begin{abstract}
LIA Pamulang Language Institute is a non-formal educational institution that has not utilized the website as a tool in doing the processing of the results of learning activities of students. This institution still uses Report Sleep as a medium of information delivery of student activities. Wherein a teacher records the student's score using a monthly form whose data is recapitulated into a special form done every three months. This process takes a lot of time so that the delivery of information becomes less effective and often students do not convey the Report Sleep received from LIA Pamulang to their parents. The use of paper in Report Sleep is also very susceptible to damage or loss. This design uses software development model with waterfall method and Model-View-Controller concept as approach of website development built. The results of this research is a website design that helps students or parents in accessing final score information easily and quickly through the internet, help the LIA Pamulang in store score data integrated with the database and do the processing and delivery of value information becomes faster, as well as having a wide range of libraries, easy maintenance and system updates by an individual or a team of developers.
\end{abstract}

Keywords : Information Systems, Scores Processing, Courses

\begin{abstract}
ABSTRAK
Lembaga Bahasa LIA Pamulang merupakan sebuah instansi pendidikan non-formal yang belum memanfaatkan website sebagai alat bantu dalam melakukan pengolahan nilai hasil kegiatan belajar siswanya. Lembaga ini masih menggunakan Report Sleep sebagai media penyampaian informasi hasil kegiatan siswanya. Di mana, seorang pengajar mencatat nilai siswa menggunakan sebuah formulir bulanan yang datanya direkapitulasi ke dalam formulir khusus yang dikerjakan setiap tiga bulan sekali. Proses ini membutuhkan waktu yang tidak sedikit sehingga penyampaian informasi menjadi kurang efektif dan seringkali siswa tidak menyampaikan Report Sleep yang telah diterima dari pihak LIA Pamulang kepada orang tua mereka. Penggunaan kertas dalam Report Sleep juga sangat rentan terhadap kerusakan atau kerugian. Perancangan ini menggunakan model pengembangan software dengan metode waterfall dan konsep Model-View-Controller sebagai pendekatan pengembangan website yang dibangun. Hasil dari penelitian ini adalah sebuah rancang website yang membantu siswa atau orang tua siswa dalam mengakses informasi nilai secara mudah dan cepat melalui jaringan internet, membantu pihak LB LIA Pamulang dalam menyimpan data nilai yang terintegrasi dengan database dan melakukan proses pengolahan dan penyampaian informasi nilai menjadi lebih cepat, serta memiliki jangkauan pustaka yang luas, perawatan dan pembaruan sistem yang mudah dilakukan oleh individu atau tim pengembang.
\end{abstract}

Kata kunci : Sistem Informasi, Pengolahan Nilai, Bimbingan Belajar 


\section{Pendahuluan}

Menurut Darmawan dalam Wardani (2012): pendidikan merupakan infrastruktur yang terpenting khususnya dalam pengembangan potensi individu, dan umumnya dalam pengembangan potensi bangsa. Untuk itu, upaya pengembangan kualitas pendidikan merupakan hal yang mutlak untuk mendapatkan perhatian. Dengan dikembangkannya teknologi pendidikan, diharapkan adanya peningkatan yang signifikan dalam sektor pendidikan, baik dalam kualitas pendidikan ini dapat meliputi peningkatan kualitas materi ajar, pemahaman siswa, sekaligus kompetensi para pengajarnya.

Pentingnya pendidikan dalam perannya mencerdaskan kehidupan bangsa telah melahirkan banyak pihak untuk berkontribusi aktif dalam penyelenggaraannya, baik di bidang formal maupun nonformal. Khususnya dalam bidang non-formal, (Wardani, 2013) memaparkan bahwa bimbingan belajar saat ini masih menjadi pilihan bagi para pelajar untuk memperluas pengetahuan dan menambah jam belajar serta menjadikannya sebagai media untuk belajar bersama teman dan berinteraksi dengan guru dalam kondisi yang lebih santai.

Bimbingan belajar juga turut memperhatikan pentingnya sisi pengolahan nilai pada suatu masa pendidikan. Hal ini juga bersesuaian dengan hal yang dikemukakan oleh Wardani (2013) bahwa nilai merupakan salah satu komponen penting dalam kegiatan belajar mengajar di sekolah yang nantinya menjadi input yang diharapkan dapat menjadi output yang dapat mengimbangi bahkan mengembangkan nilai masingmasing siswa. (Kurniawan, Migunani, \& Hidayat, 2013) memaparkan bahwa penilaian merupakan suatu bentuk evaluasi terhadap siswa selama mengikuti proses belajar mengajar (PBM) atau kegiatan belajar mengajar (KBM) dalam suatu institusi pendidikan, mulai dari tingkat dasar sampai perguruan tinggi. Akan tetapi, menurut Nursahid, Riasti, \& Purnama (2015) bahwa proses pengolahan nilai rapor seringkali membutuhkan tenaga dan waktu yang tidak sedikit, terutama jika proses tersebut dilakukan secara manual. Oleh sebab itu, peran teknologi menjadi sangat penting pada sisi ini. Ini bersesuaian dengan yang dimaksudkan oleh Membara, Yulianti, \& Kanedi (2014) bahwa teknologi menjadi suatu hal yang dibutuhkan oleh semua orang, karena dengan adanya teknologi informasi seseorang akan lebih cepat mengetahui informasi yang ada di sekitarnya. Akibatnya, kebutuhan manusia akan teknologi semakin tinggi karena dapat membantu efektivitas dan efisiensi suatu pekerjaan (Kamran \& Kharie, 2016). Peran teknologi informasi khususnya aplikasi website akan membantu pihak lembaga bimbingan belajar dalam melakukan pengolahan nilai rapor. Selain karena alasan kemudahan dan ramah dalam pengelolaannya, Membara, Yulianti, \& Kanedi (2014) memaparkan bahwa website dapat diakses oleh siapa saja dan di mana saja tanpa dibatasi waktu dan tempat.

Lembaga Bahasa (LB) LIA Pamulang merupakan sebuah instansi pendidikan non-formal telah menggunakan teknologi website. Akan tetapi, LB LIA Pamulang belum memanfaatkan website sebagai alat bantu dalam melakukan pengolahan nilai hasil kegiatan belajar peserta didiknya. Lembaga ini masih menggunakan lembaran semacam rapor yang disebut dengan Report Sleep sebagai media penyampaian informasi hasil kegiatan belajar siswanya. Di mana, seorang pengajar mencatat nilai kehadiran, nilai rata-rata harian, hasil tes lisan, dan hasil tes tertulis siswanya menggunakan sebuah formulir bulanan. Formulir bulanan ini direkapitulasi datanya ke dalam formulir khusus yang dikerjakan setiap tiga bulan sekali. Kemudian diberikan kepada pihak supervisor untuk dikoreksi dan disampaikan kepada bagian administrasi untuk menghitung nilai akhir dan mencetak hasilnya ke dalam sebuah Report Sleep yang diberikan kepada siswa langsung dan dicantumkan di majalah dinding. Proses ini membutuhkan waktu yang tidak sedikit sehingga penyampaian informasi menjadi kurang efektif. Hal lainnya adalah seringkali Report Sleep yang telah diterima siswa dari pihak LB LIA Pamulang tidak disampaikan kepada orang tua mereka dan penggunaan media kertas pada Report Sleep sangat rentan terhadap kerusakan atau kehilangan.

Berdasarkan masalah tersebut, dibutuhkan website yang mampu menangani permasalahan ketidakefektifan proses pengolahan nilai, menyajikan informasi nilai siswa secara cepat dan mudah, serta dapat dikembangkan dan dirawat dengan mudah oleh para pengembang. Dalam hal ini, website yang mengusung konsep Model-View-Controller (MVC) adalah website dengan konsep yang sangat tepat.

\section{Pembahasan}

\section{A. Metode Penelitian}

Pada penyusunan laporan penelitian ini, peneliti meneliti LB LIA Pamulang sebagai objek penelitian. Menurut Sugiyono (2013, hal. 224) teknik pengumpulan data merupakan langkah yang paling strategis dalam penelitian, karena tujuan utama dari penelitian adalah mendapatkan data. Adapun teknik pengumpulan data yang peneliti lakukan sebagai berikut:

1. Observasi (Observation)

Peneliti melakuan observasi atau pengamatan langsung terhadap sistem yang berjalan dalam pengolahan nilai di LB LIA Pamulang.

2. Wawancara (Interview)

Peneliti melakukan wawancara kepada Kepala atau Manajer Cabang dan bagian administrasi LB LIA Pamulang untuk memperoleh data-data yang terkait langsung dengan permasalahan yang diteliti, yakni pengolahan nilai siswa di LB LIA Pamulang.

3. Studi Pustaka (Library Research)

Peneliti mencari referensi dari buku-buku, jurnal, penelitian sejenis, dan literatur-literatur lainnya yang turut mendukung penyelesaian penulisan penelitian ini, yakni mencari informasi tentang definisi nilai, langkah-langkah dalam perancangan website, dan metode yang dipakai dalam penelitian ini. 
Pada penelitian yang dilakukan, peneliti menggunakan metode waterfall dalam tahap perancangan website. Rosa \& Shalahuddin (2016, hal. 28) menyatakan bahwa waterfall sering juga disebut model sekuensial linier (sequential linear) atau alur hidup klasik (classic life cycle), metode ini digunakan karena tahap-tahap yang dilakukan berurut sehingga memudahkan untuk menentukan waktu pengerjaan dari setiap tahapnya. Berikut ini adalah tahapan dalam metode waterfall.

1. Analisa Kebutuhan

Pada LB LIA Pamulang, peneliti mengidentifikasi masalah, yakni meliputi pembagian hasil kegiatan belajar siswa atau Report Sleep yang sedang berjalan saat ini, dan melakukan pengembangan dengan membuat perancangan mengenai data-data masukan yang dibutuhkan, pemrosesan data nilai, sampai dengan menghasilkan keluaran atau output guna meningkatkan efektifitas dan efisiensi dari pembagian hasil kegiatan belajar siswa atau Report Sleep sebelumnya.

2. Desain

Pada tahapan ini, peneliti membuat rancangan halaman antarmuka website yang akan dibangun, membuat Entity Relationship Diagram (ERD) sebagai gambaran alur database, Logical Record Structure (LRS) sebagai gambaran struktur database, Unified Modeling Language (UML) sebagai gambaran fungsional utamanya, dan menggunakan bahasa pemrograman berbasis Hypertext Preprocessor (PHP).

3. Code Generation

Pada tahapan ini, peneliti menerapkan desain ke dalam tools pendukung, yakni perangkat lunak yang digunakan untuk merancang hasil dari tahapan desain, dengan menggunakan Laravel Framework 5.3 yang mengusung konsep pengembangan web Model-View-Controller (MVC) dengan jangkauan pustaka yang luas, dan dapat dikembangkan baik secara individu maupun tim pengembang, text editor menggunakan Sublime Text 3, server lokal menggunakan Xampp 5.6.28, dan perancangan database dengan MySQL.

4. Testing

Pada tahap testing, peneliti menguji website yang telah dibangun menggunakan metode black box testing, dengan tujuan untuk meminimalisir kesalahan (error) dan memastikan keluaran yang dihasilkan sistem sesuai dengan yang diinginkan.

5. Implementasi

Setelah melakukan tahapan pengujian, kemudian peneliti mengadakan pelatihan guna memberi keterampilan dan pemahaman kepada user untuk menggunakan sistem baru yang telah dibuat.

6. Support

Tahapan akhirnya adalah dukungan, di mana pada tahapan ini peneliti melakukan perawatan dan pengembangan sistem agar perangkat mampu beradaptasi pada lingkungan baru yang seringkali berubah-ubah.

\section{Hasil dan Pembahasan}

Dari hasil penelitian yang dilakukan berdasarkan metode penelitian, diperoleh suatu website pengolahan nilai sebagai berikut:

1. Tahapan Analisis

Spesifikasi usulan kebutuhan sistem (system requirement) dari website pengolahan nilai dengan menggunakan konsep Model-View-Controller (MVC) pada LB LIA Pamulang yang dirancang sebagai berikut:

a. Halaman Siswa

1) Siswa melakukan login

2) Siswa dapat mengubah profil

3) Siswa dapat melihat nilai

4) Siswa dapat mengubah password

b. Halaman Admin

1) Admin melakukan login

2) Admin dapat mengelola data siswa

3) Admin dapat mengelola data level/term

4) Admin dapat mengelola data kelas

5) Admin dapat mengelola data nilai siswa

6) Admin dapat mencetak sertifikat

7) Admin dapat mengubah password

Berdasarkan tahapan analisis kebutuhan sistem, diperoleh use case diagram, activity diagram, component diagram dan deployment diagram sebagai berikut:

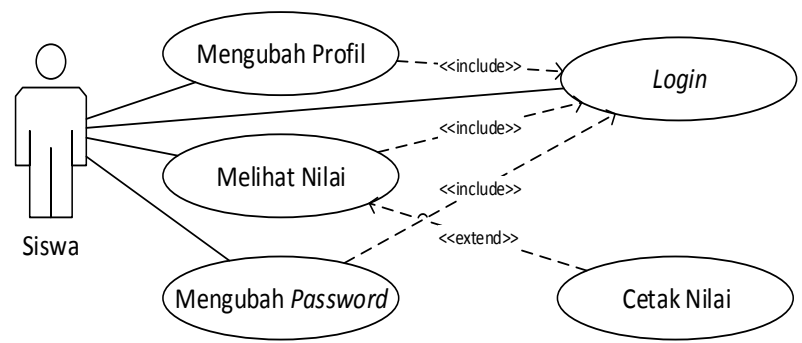

Gambar 1. Usecase Diagram Siswa

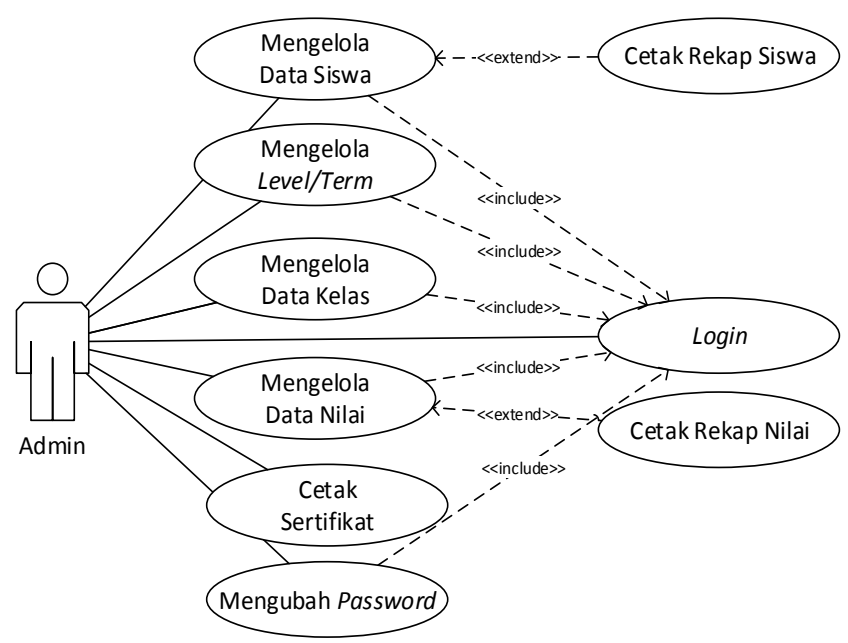

Gambar 2. Usecase Diagram Admin 


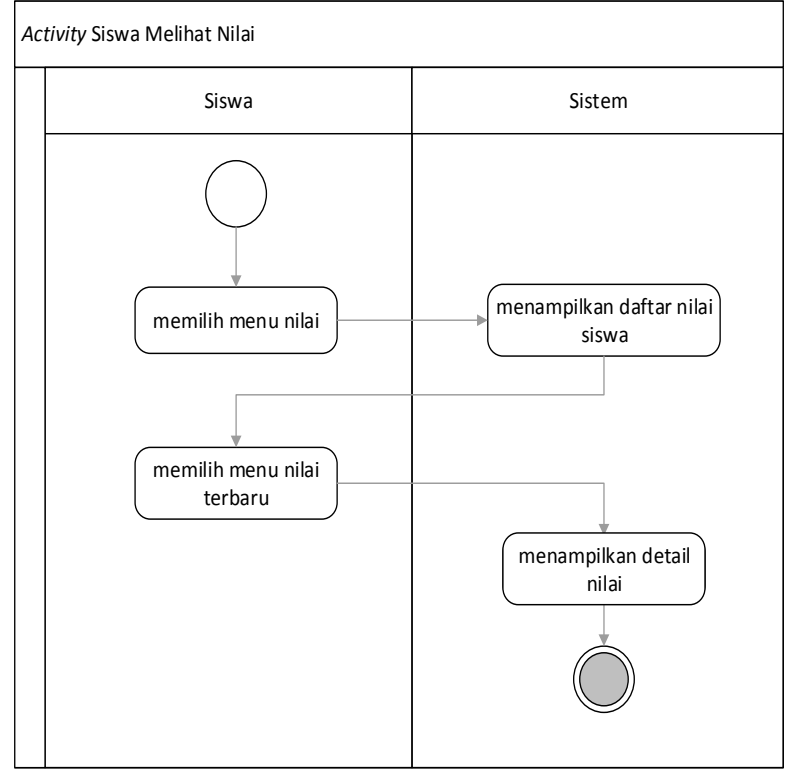

Gambar 3. Siswa Melihat Nilai

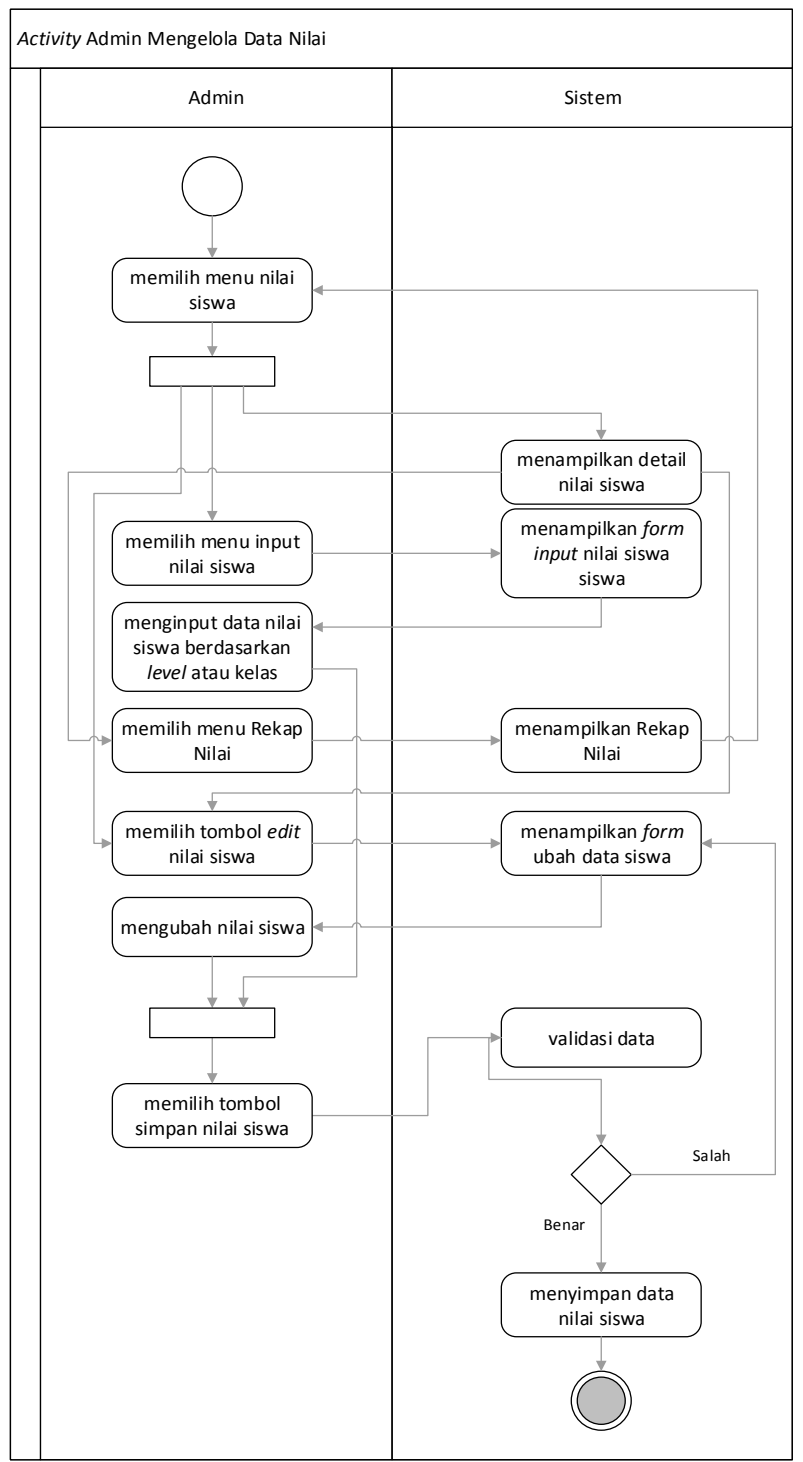

Gambar 4. Activity Diagram Admin Melihat Nilai
Component diagram menggambarkan stuktur dan hubungan termasuk ketergantungan antar komponen perangkat lunak yang ada pada suatu sistem yang dibangun. Berikut merupakan struktur proses yang terdapat dalam website pengolahan nilai siswa pada LB LIA Pamulang yang digambarkan melalui component diagram.

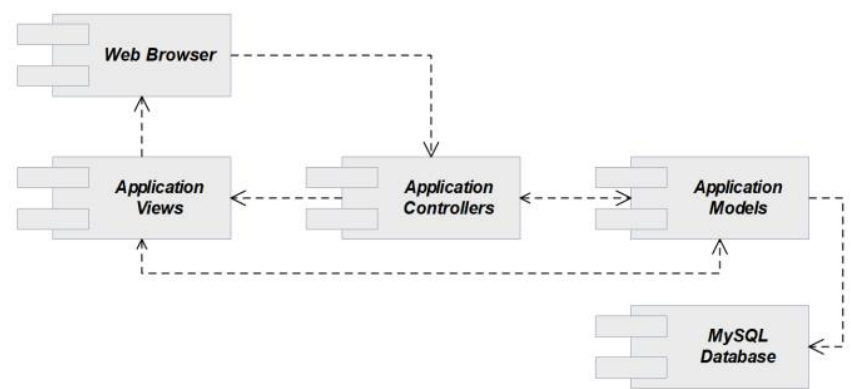

Gambar 5. Component Diagram

Deployment diagram menggambarkan tata letak sebuah sistem dan konfigurasi saat aplikasi dijalankan, menunjukkan bagian-bagian perangkat lunak yang digunakan untuk mengimplementasikan sebuah sistem dan keterhubungan antara komponen perangkatperangkat keras yang ada di dalamnya. Berikut adalah bentuk deployment diagram pada website pengolahan nilai pada LB LIA Pamulang.

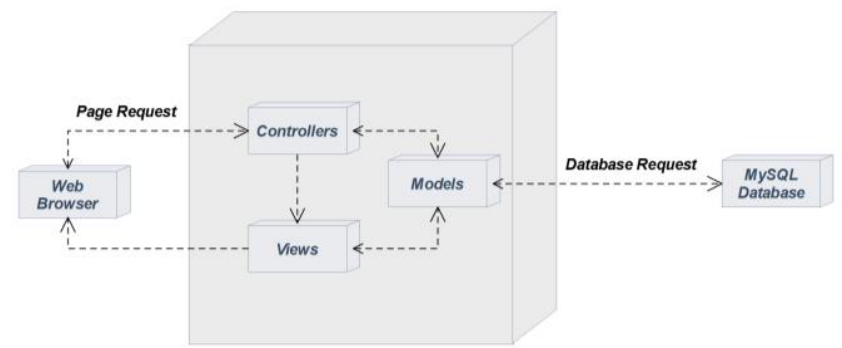

Gambar 6. Deployment Diagram

2. Desain

Analisa kebutuhan dilakukan untuk menentukan rancangan awal dari sistem yang akan dibangun. Maka impelementasinya dilanjutkan pada tahap desain. Berikut ini merupakan tahap desain yang diterapkan dalam perancangan website pengolahan nilai LB LIA Pamulang. Adapun tampilan rancang desain dari sisi database menggunakan Entity Relationship Diagram (ERD) dan Logical Record Structure (LRS) berdasarkan hasil tahapan analisa kebutuhan sistem sebagai berikut. 


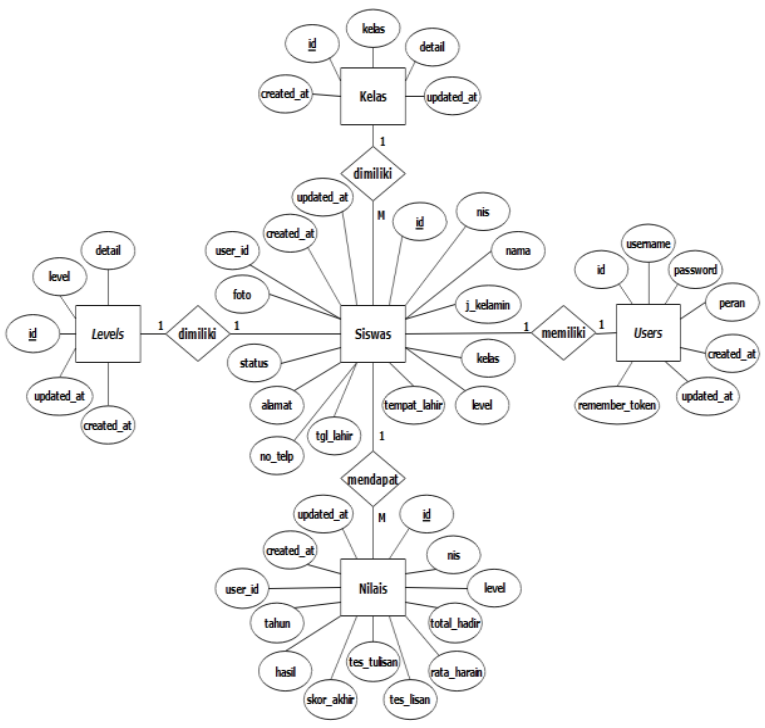

Gambar 7. Entity Relationship Diagram (ERD)

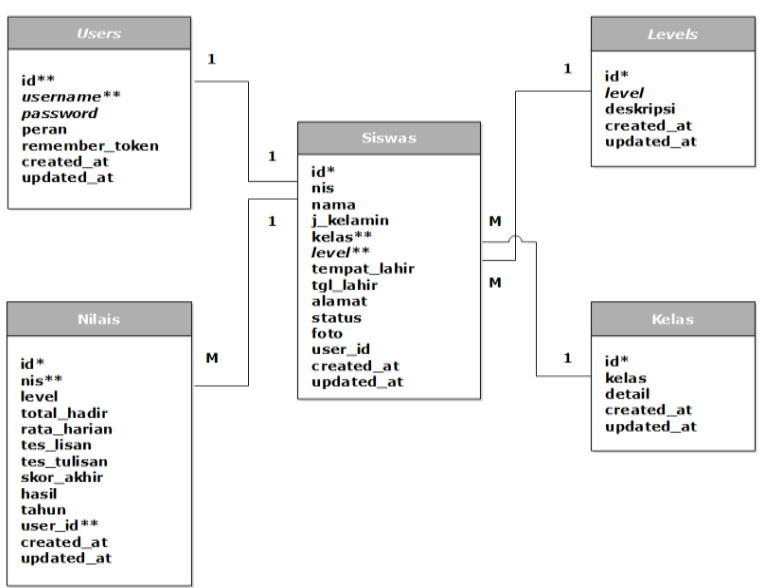

Gambar 8. Logical Record Structure (LRS)

Pada sisi spesifikasi halaman website pengolahan nilai pada LB LIA Pamulang, dibagi menjadi dua rancangan halaman, yaitu halaman siswa dan halaman admin sebagai berikut:

a. Halaman Siswa Melihat Nilai

Gambar 9 menjelaskan sebuah tampilan aplikasi sistem yang menyajikan tampilan dan informasi daftar nilai siswa yang diurutkan berdasarkan data terbaru, terakhir, atau ter-update.

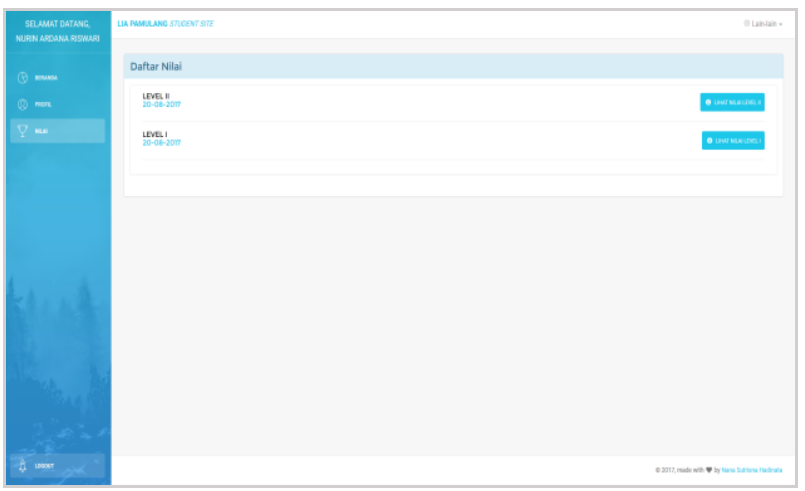

Gambar 9. Halaman Nilai Siswa b. Halaman Siswa Melihat Detail Nilai

Gambar 10 menjelaskan sebuah tampilan aplikasi sistem yang menyajikan tampilan dan informasi nilai siswa lebih rinci setelah siswa memilih tombol 'lihat nilai'.

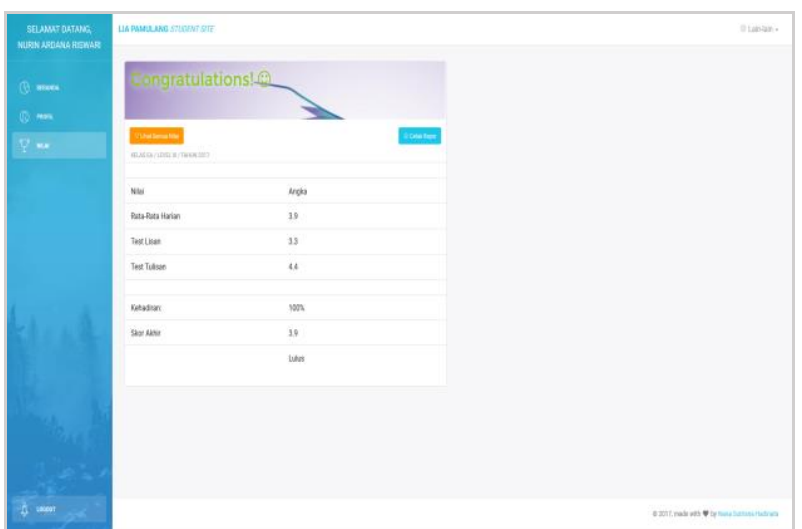

Gambar 10. Halaman Detail Nilai Siswa

c. Halaman Admin Kelola Data Nilai

Pada Gambar 11, disajikan tampilan aplikasi sistem yang memberikan informasi kepada admin mengenai data nilai siswa yang dapat ditambah, dihapus, atau diupdate apabila ada perubahan atau kekeliruan pada data nilai yang telah disimpan.

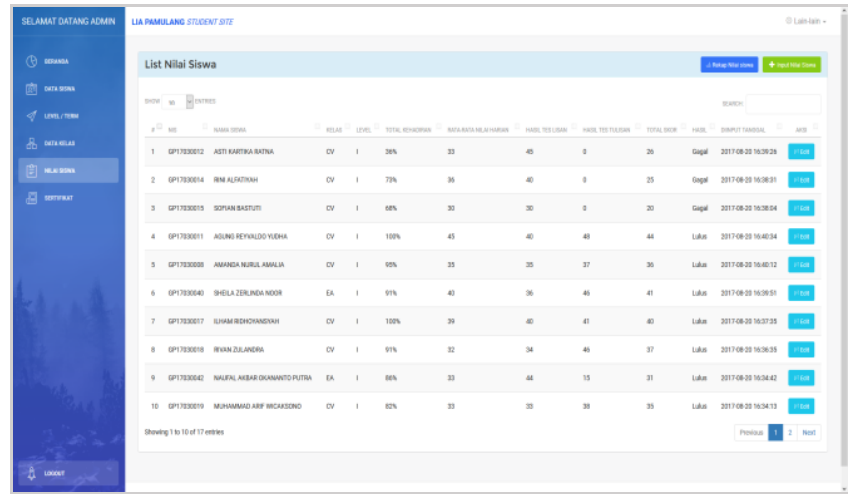

Gambar 11. Halaman Admin Kelola Data Nilai

\section{Kesimpulan}

Lembaga Bahasa (LB) LIA Pamulang belum sepenuhnya memanfaatkan website sebagai alat bantu dalam melakukan pengolahan hasil belajar atau nilai peserta didiknya. Pencatatan nilai yang dikerjakan dengan banyak formulir membutuhkan waktu tidak sedikit yang mengakibatkan penyampaian informasi nilai menjadi kurang efektif dan penyampaian Report Sleep yang menggunakan media kertas tersebut sangat rentan terhadap kerusakan atau kehilangan. Sehingga dibutuhkan sebuah website yang memiliki jangkauan pustaka yang luas, mudah dirawat atau dikembangkan oleh individu atau tim pengembang, di mana website ini akan mampu menangani permasalahan ketidakefektifan proses pengolahan nilai, dan menyajikan informasi nilai siswa secara cepat dan mudah. 


\section{Daftar Pustaka}

Aminudin. 2015. Cara Efektif Belajar Framework Laravel (hal. 13). Yogyakarta: Lokomedia.

Huda, M. (2010). Membuat Aplikasi Database Dengan Java, MySQL, Dan NetBeans. Jakarta: Elex Media Komputindo.

Ladjamudin, A.-B. bin. 2013. Analisis dan Desain Sistem Informasi (hal. 142). Yogyakarta: Graha Ilmu.

Madcoms. 2012. Madcoms. JavaScript untuk Membangun Website Profesional (hal. 2). Yogyakarta: ANDI.

Nugroho, A. 2010. Rekayasa Perangkat Lunak Berorientasi Objek Dengan Metode USDP (hal. 62). Yogyakarta: ANDI.

Prayitno, S. 2013. YII Framework: Menguasai Framework PHP Terbaik (hal. 4). Yogyakarta: Lokomedia.

Rosa, A. S., \& Shalahuddin, M. 2016. Rekayasa Perangkat Lunak (Terstruktur dan Berorientasi Objek). Bandung: Informatika.

Sadeli, M. 2014. Aplikasi Bisnis dengan PHP \& MySQL (hal. 2). Palembang: Maxikom.

Winarno, E., Eng, M., Ali, Z., \& Community, S. 2014. 24 Jam Belajar PHP. Jakarta: Elex Media Komputindo.

Yuhefizar. 2008. 10 Jam Menguasai Internet: Teknologi dan Aplikasinya (hal. 5). Jakarta: Elex Media Komputindo. 